\title{
Brain glucose utilisation in acquired childhood aphasia associated with a sylvian arachnoid cyst: recovery after shunting as demonstrated by PET
}

\author{
A G De Volder, Ch Michel, C Thauvoy, G Willems, G Ferrière
}

\begin{abstract}
Regional brain glucose utilisation was investigated with PET and fluorodeoxyglucose (FDG) in a case of epileptic aphasia (Landau-Kleffiner syndrome) associated with a left sylvian arachnoid cyst. CT and MRI had failed to disclose any mass effect of the cyst on surrounding brain structures. Sequential metabolic measurements showed a comparable pronounced hypometabolism in cortical regions around the cyst, involving speech areas, and suggested mild but chronic compression of the developing brain. After placement of a cyst-peritoneal shunt system, significant metabolic improvement occurred in all cortical regions, especially the inferior frontal gyrus and the perisylvian area, with predominant residual deficit in the left superior temporal gyrus. These findings were correlated with a pronounced increase in word fluency and slower progress in verbal auditory comprehension. This report suggests that PET is able to evaluate the functional disturbances associated with expanding arachnoid cysts, and to follow the neurological improvement after drainage.
\end{abstract}

$(\mathcal{F}$ Neurol Neurosurg Psychiatry 1994;57:296-300)

Arachnoid cysts are intra-arachnoid collections of cerebrospinal fluid. Congenital in origin, they are associated with epilepsy in about $18 \%$ of patients and may cause neurological deficit through expansion that can compress normal neural tissue. ${ }^{12}$ Although recent advances have elucidated the pathogenesis and radiological manifestations of arachnoid cysts, the choice of diagnostic and therapeutic methods remains controversial. ${ }^{3}$ This led us to investigate the regional glucose metabolism in a case of epileptic aphasia associated with an arachnoid cyst located in the sylvian fissure, near cortical speech areas.

So far as we know, studies of brain metabolism in children with arachnoid cysts have not been reported. As glucose, with oxygen, is the main substrate of the brain at all ages, regional brain glucose utilisation provides an index of local neural function. The present work describes three studies of glucose metabolism performed in the same patient, at two year intervals, before and after cyst-peritoneal shunting. The results obtained in this individual case suggest a strong relation between regional brain metabolism, functional consequences of expanding cysts, and response to drainage.

\section{Case report}

The patient was a white male aged 10 years at the time of the first metabolic study. Early psychomotor development was uneventful, with an apparently normal acquisition of language. A progressive decline of verbal fluency was first noted at age five, and complete mutism became established in a few months. This severe aphasia was associated with verbal auditory agnosia, aggressive behaviour, hyperkinesis, and clumsiness. During this period at least one atypical absence with palpebral myoclonic jerks was seen. The child was considered to be psychotic, however, and remained unmedicated. A CT scan, performed at age seven, revealed the presence of an extraparenchymal cystic mass containing fluid in the left middle cranial fossa, extending over the cerebral convexity to the frontoparietal region. Although the portion of the skull covering the cyst was bulging and thinned, there was no distortion of the midline, nor apparent displacement of adjacent brain structures and the collection was considered to be a benign arachnoid cyst. Studies by EEG disclosed bilateral multifocal spike and spike-wave complexes, with a slight predominance over the left temporal region. Treatment with valproate abolished the discharges but did not improve the aphasic disturbances. Six months later, a sleep EEG revealed continuous spike-wave activity during slow sleep, a condition known as electrical status epilepticus of sleep. Treatment with ACTH resulted in a normalisation of sleep, but did not ameliorate the speech disorder.

The child was still treated with valproate when referred to our institution. Detailed general and neurological examinations were normal except for aphasia and motor hyperactivity. Five words could be uttered laboriously in a correct context and verbal comprehension was reduced to the child's name. The intensity of speech dysfunction had forced the patient to develop the use of a sign language, gestures, drawings, and multiple facial mimics expressing emotion. The disturbance in decoding sounds extended far beyond the verbal field. Acquired deafness was ruled out by auditory evoked potentials. EEG displayed normal background rhythms with slow $\theta$-waves in the temporal regions and rare atypical spike-wave complexes $(3-4 \mathrm{~Hz}$ ) 
over the left temporoparietal region. Sleep abnormalities had disappeared and wake epileptogenic paroxysms subsided in a few weeks. An MRI scan confirmed the presence of a mega-arachnoid cyst of the sylvian fissure, extending to the left parietal convexity (figure). MRI was helpful in delineating the sharp irregular medial cyst's margin and in excluding the existence of associated cerebral atrophy. There was no overlying brain tissue, a finding commonly seen in porencephaly. Remedial treatment of the speech disorder included labial reading, the set up of a communication tool with pictograms, pictures and written words, rehabilitation of voice and articulation, decoding of sounds and verbal messages, and learning of syntaxic structures by a combination of contemporary methods of speech training (Carrier, Dubard, and Pace). The sequential language testing consisted of analysis of spontaneous speech, object naming, repetition, auditory discrimination, and comprehension.

Extradural pressure monitoring, performed eight months after the first PET study, gave values ranging from 10 to $20 \mathrm{mmHg}$ in close proximity to the cystic lesion. In the absence of obvious symptoms of intracranial hypertension, this was considered a sufficient reason not to operate. Moreover, during the two first years of speech therapy there was a gradual progression in language output, with increase of vocabulary up to 100 words. The auditory agnosia subsided, despite some residual disability to differentiate the vowels. The child became able to understand simple orders and to spot two critical units in a sentence (success rate $40 \%$ ). The spontaneous speech production still remained limited however, with verbal stereotypes and dysarthria. This initial recovery phase was followed by a stagnant period during which the speech improved very little, and the boy became discouraged. As similar metabolic results were obtained with the second PET study, surgery was considered necessary. A cyst-peritoneal shunting was placed 10 months later, and led to diminished cyst size and clinical improvement. Eight months after the shunting procedure, language functions were reassessed. There was a significant increase in verbal fluency and articulation, with spontaneous production of word combinations to form elaborate agrammatic sentences. Receptive function improved moderately, but success rate for recognition of two critical elements increased to $90 \%$. Neuropsychological studies of higher brain functions showed a normal IQ (93) on the Hiskey-Nebraska scale. After the last PET scan study, carried out nine months
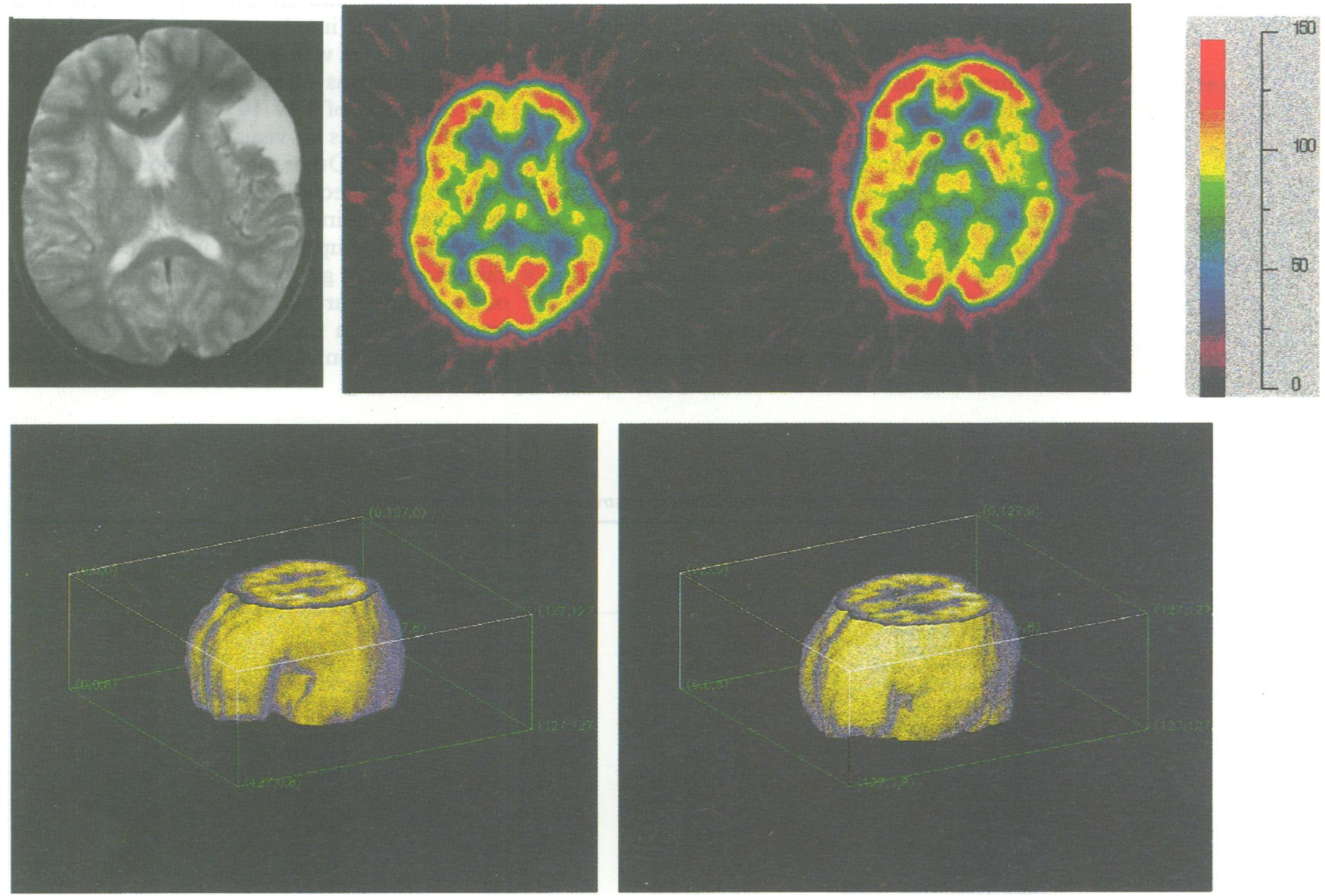

Figure Top: MRI (upper left), and PET images at the level of the basal ganglia, before (upper middle) and after (upper right) shunting. The right side of the head is to the reader's left. On MRI image (T2-weighted, 1.5 T:TR $2180 \mathrm{~ms}$, TE $100 \mathrm{ms,}$ thickness $8 \mathrm{~mm}$ ) the irregular inner wall of the left sylvian arachnoid cyst is clearly delineated, without evidence of associated dysplasia. Preoperative PET image shows prominent hypometabolism in cortical regions surrounding the cyst, including speech areas. On the postoperative PET there is a pronounced improvement of glucose utilisation in all brain areas, with residual deficit in the left superior temporal gyrus. Colour bars are percentage of mean grey metabolism. For a better comparison of the regional pattern, each study is rescaled to its own maximum. Bottom: Three dimensional reconstruction of the metabolic surface of the brain, preoperatively (left) and after shunting (right), showing the re-expansion of functional brain tissue after drainage. 
after surgery, valproate dose was slowly reduced without an intercurrent event.

\section{Methods}

Positron emission data were collected with an ECAT III one ring tomograph and the fluorodeoxyglucose (FDG) autoradiographic method, following a protocol described previously. ${ }^{4}$ Eight brain levels were studied sequentially in the canthomeatal orientation, starting 35 minutes after FDG injection. Images with a thickness of $15 \mathrm{~mm}$ full width at half maximum, were acquired at $1 \mathrm{~cm}$ intervals and reconstructed at an in plane resolution of 9 $\mathrm{mm}$ full width at half maximum. Attenuation correction was carried out with a contour finding algorithm and an effective attenuation coefficient of $0.088 . .^{5}$ When an arterial input function was available, images of emission density were transformed into maps of glucose metabolism. ${ }^{6}$ Irregular regions of interest were drawn on the images by reference to common neuroanatomical hallmarks, to MRI scan, to a neuroanatomical atlas, ${ }^{7}$ and to a series of normal anatomical brain slices prepared in the same orientation. The reproducibility of the procedure was estimated in test-retest studies in resting volunteers, giving an intraindividual coefficient of variation of $6.5 \%$ in mean grey-matter metabolism. ${ }^{8}$

Parents gave their informed consent before the PET studies, the protocol of which had been approved by the Medical Ethics Committee of the University of Louvain. The patient fasted for at least four hours and was studied (three times at two year intervals) at rest, in the supine position, with eyes open and ears unplugged. Concentrations of valproate in blood ranged between 60 and 80 $\mu \mathrm{g} / \mathrm{ml}$. No sedation was given. FDG (100 $\mu \mathrm{Ci} / \mathrm{kg}$ body weight) was injected intravenously. For input curve determination, a 24 gauge catheter (Abbocath) was inserted into the radial artery under local anaesthesia with bupivacain. Because for technical reasons no arterial input curve could be obtained in the two preoperative studies, all regional values of FDG uptake were expressed as a percentage of an average activity defined over large areas of cortical grey matter. These were compared with reference values obtained in 33 young healthy volunteers (mean age 22 years), studied at rest with eyes closed. Regional values were considered abnormal when deviating by more than 2 SD from control data.

\section{Results}

The table shows the relative metabolic values. A perfect match in the head's position between the three studies could not be achieved. The data collection mode was such, however, that the entire volume of cortical areas surrounding the cyst was sampled in adjacent, slightly overlapping sections. Only well defined regions of interest were matched on corresponding images in the three analyses. It is apparent that preoperative studies gave reproducible results: relative metabolic rates were significantly decreased (2 SD criterion) in all cortical structures adjacent to the cyst, with a clear deficit in the left insula. There was a profound decrease of FDG uptake in the inferior frontal region including Broca's area, and in the superior temporal gyrus. A slight involvement of the whole left temporal cortex was disclosed, though not significant in terms of relative rates. There was also evidence of low FDG accumulation in the left thalamus on visual inspection of metabolic images. Other brain regions were not significantly affected. There was no cerebellar asymmetry. Nine months after the shunting procedure, the uptake map indicated a significant increase in glucose utilisation in all previously affected areas. There was a prominent improvement in the left insular region and in the inferior frontal gyrus, including Broca's

Relative values of glucose utilisation in control subjects and the patient

\begin{tabular}{|c|c|c|c|c|}
\hline \multirow[b]{2}{*}{ Brain regions } & \multirow[b]{2}{*}{$\begin{array}{l}\text { Control subjects } \\
\text { (mean }(S D))\end{array}$} & \multicolumn{3}{|l|}{ Patient } \\
\hline & & $\begin{array}{l}\text { Study } 1 \\
\text { (preoperative) }\end{array}$ & $\begin{array}{l}\text { Study } 2 \\
\text { (preoperative) }\end{array}$ & $\begin{array}{l}\text { Study } 3 \\
\text { (postoperative) }\end{array}$ \\
\hline $\begin{array}{l}\text { Right frontal cortex } \\
\text { Left frontal cortex } \\
\text { Right temporal cortex } \\
\text { Left temporal cortex } \\
\text { Right parietal cortex } \\
\text { Left parietal cortex } \\
\text { Right visual cortex } \\
\text { Left visual cortex } \\
\text { Right insula } \\
\text { Left insula } \\
\text { Right striatum } \\
\text { Left striatum } \\
\text { Right thalamus } \\
\text { Left thalamus } \\
\text { Right frontomesial cortex } \\
\text { Left frontomesial cortex } \\
\text { Right inferior frontal gyrus } \\
\text { Left inferior frontal gyrus } \\
\text { Right superior temporal gyrus } \\
\text { Left superior temporal gyrus }\end{array}$ & $\begin{array}{r}111 \cdot 23(5 \cdot 46) \\
108 \cdot 67(5 \cdot 12) \\
98 \cdot 66(4 \cdot 03) \\
97 \cdot 99(3 \cdot 79) \\
94 \cdot 34(4 \cdot 41) \\
93.91(4 \cdot 29) \\
99 \cdot 79(7 \cdot 04) \\
99 \cdot 70(6 \cdot 14) \\
98 \cdot 74(4 \cdot 40) \\
96 \cdot 27(4 \cdot 26) \\
99 \cdot 63(4 \cdot 37) \\
99 \cdot 44(4 \cdot 74) \\
90 \cdot 53(5 \cdot 59) \\
89 \cdot 14(5 \cdot 75) \\
103 \cdot 87(4 \cdot 86) \\
104 \cdot 34(4 \cdot 44) \\
112 \cdot 02(5 \cdot 04) \\
109 \cdot 75(5 \cdot 59) \\
99 \cdot 58(3 \cdot 66) \\
97 \cdot 11(3 \cdot 84)\end{array}$ & $\begin{array}{l}110 \cdot 46 \\
108 \cdot 09 \\
104 \cdot 47 \\
93 \cdot 18^{\star} \\
103 \cdot 29 \\
97 \cdot 59 \\
117 \cdot 76 \\
111 \cdot 97 \\
94 \cdot 43 \\
67 \cdot 58^{\star \star} \\
100 \cdot 50 \\
97 \cdot 39 \\
90 \cdot 56 \\
84 \cdot 21 \\
99 \cdot 52 \\
101 \cdot 99 \\
108 \cdot 46 \\
86 \cdot 92^{\star \star} \\
97 \cdot 39 \\
66 \cdot 74^{\star \star}\end{array}$ & $\begin{array}{c}108 \cdot 42 \\
107 \cdot 11 \\
104 \cdot 06 \\
93 \cdot 31^{\star} \\
101 \cdot 33 \\
98 \cdot 87 \\
116 \cdot 88 \\
114 \cdot 78 \\
94 \cdot 34 \\
79 \cdot 27^{\star \star} \\
97 \cdot 86 \\
98 \cdot 80 \\
88 \cdot 35 \\
82 \cdot 25^{\star} \\
103 \cdot 37 \\
102 \cdot 27 \\
107 \cdot 44 \\
84 \cdot 28^{\star \star} \\
97 \cdot 35 \\
66 \cdot 06^{\star \star}\end{array}$ & $\begin{array}{r}113 \cdot 95 \\
118 \cdot 76 \\
99 \cdot 10 \\
96 \cdot 54 \\
97 \cdot 22 \\
95 \cdot 67 \\
111 \cdot 40 \\
111 \cdot 79 \\
98 \cdot 25 \\
90 \cdot 38^{\star} \\
100 \cdot 49 \\
101 \cdot 13 \\
92 \cdot 22 \\
94 \cdot 51 \\
102 \cdot 54 \\
106 \cdot 56 \\
114 \cdot 19 \\
101 \cdot 09^{\star} \\
98 \cdot 19 \\
82 \cdot 02^{\star \star}\end{array}$ \\
\hline
\end{tabular}

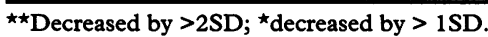

Metabolic rates are expressed in \% of mean grey metabolism. Studies 1 and 2 were performed preoperatively at two year intervals; the third analysis was carried out nine months after cyst-peritoneal shunting. 
area. A significant residual deficit was found in the left superior temporal gyrus only. Posttreatment values were within the normal range in the thalamus. Absolute quantification, obtained in the last study, yielded a value of mean glucose metabolism of 50.98 $\mu \mathrm{mol} / 100 \mathrm{~g} / \mathrm{min}$, which is in the normal range for our laboratory. Absolute regional values were in agreement with the relative uptake maps. The figure shows the PET images

\section{Discussion}

These studies showed a significant decrease of glucose utilisation in all grey structures surrounding the arachnoid cyst, with predominant alterations at the level of the posterior inferior frontal region, including Broca's area, in the superior temporal gyrus, and in the left thalamus. This uptake map was consistent with the clinical signs of acquired global, both motor and sensory, aphasia. After cystperitoneal shunting, a significant improvement in glucose metabolism was seen in the frontal areas, the insular region, and in the thalamus, whereas it was less obvious in the superior temporal gyrus. This pattern seemed strongly correlated with the clinical response, characterised by a much better language output.

The limitations of the autoradiographic PET/FDG method and its application to neurological diseases in childhood have been discussed elsewhere. ${ }^{9}$ No age matched control data are available and the rate constants have never been measured in the brains of children. The use of adult reference values is acceptable, however, because the discussion is based primarily on the regional pattern, which is reached after two years and would not change between 10 and 14. The state of alertness of the child during the procedure is extremely variable, and its assessment on an objective basis is precluded, especially in an aphasic subject. Although whole brain metabolism undergoes important variations with the emotional state and might yield slightly different results in the frontal and temporal areas, ${ }^{10}$ it could not account for the differences in the selective left perisylvian region.

The association of an intracranial arachnoid cyst with the onset of a Landau-Kleffner syndrome has not been reported so far. Although it is becoming increasingly evident that not all patients with Landau-Kleffner syndrome display the same clinical, EEG, and evolutionary features, the lack of convulsive seizures and the absences seen in the present case were atypical. The frequency of clinical attacks in Landau-Kleffner syndrome, however, is variable and ocular myoclonies have been mentioned. ${ }^{11}$ Although the precise duration of EEG paroxysms in our case is not known, there are sufficient clinical arguments to consider that the association of acquired expressive and receptive aphasia with hyperkinesis and continuous spike and wave activity during slow sleep belong to the syndrome. ${ }^{11}$ Consequently our metabolic findings may not be applicable to all patients with Landau-
Kleffner syndrome.

Notwithstanding those reservations, our study provides original data on the effects of an arachnoid cyst on regional cerebral function. The morphological appearance of the sylvian cavity (by far the most common location), its clearly defined irregular border, the bulging of the skull, and the absence of obvious structural lesions in surrounding brain areas are typical of the benign malformations of developmental origin called "congenital arachnoid cysts". ${ }^{1312}$ Those cystic masses, which can often exist around functionally important brain regions without overtly interfering with function, have sometimes been considered to be space occupying collections secondary to temporal dysgenesis, especially in the cases of epilepsy. The identical size of affected and contralateral temporal lobes on the MRI image, however, the absence of any asymmetry of the ventricles, and, above all, the extensive metabolic impairment in phylogenetically distinct brain areas argue against this hypothesis. Paetau et $a l^{13}$ recently reported the association of an arachnoid cyst with pachygyric cortex, undetected by MRI. The normal values obtained with epidural pressure monitoring were firstly considered to support the dysgenesis theory. The accuracy of this indirect measurement remains questionable, however, due to the lack of transmission of intracranial pressure to the epidural space. ${ }^{14}$ The definite diagnosis was not established by biopsy, because efforts at cyst wall excision are not devoid of morbidity, whereas the more simple shunting procedure usually provides a satisfactory outcome and is safer. Nevertheless, although some degree of temporal dysgenesis cannot be excluded, the brain tissue re-expansion after surgery argues against this hypothesis. Whatever the precise nature of the cyst, metabolic deficits were strongly correlated with clinical symptoms, and PET offered superior diagnostic information to determine whether surgery was necessary or not.

The prominent metabolic disturbances involved brain areas related to language functions. The dominant inferior frontal region and its posterior part, including Broca's area, have previously been identified as important for articulate speech and word fluency. ${ }^{15-17}$ It is a striking feature in our case that metabolism in these regions improved noticeably after surgery, whereas clinical benefit concerned predominantly speech production. By contrast the superior temporal gyrus recovered moderately. This area is considered to subserve interpretation of acoustic signals. ${ }^{16}$ In addition, as word comprehension and instructions to make judgments about speech signals seem to rely on lateralised neural systems in the left hemisphere, ${ }^{17}$ it hardly suggests that the left superior temporal gyrus would play a crucial part in the child's receptive disturbances. The pulvinar, the largest of the thalamic nuclei, projects heavily to the temporal cortex. It is tempting to suggest that the extinction of thalamic activity preoperatively was due to a functional deaf- 
ferentation, related to chronic disturbances in corticothalamic connections on the left side.

Auditory agnosia cannot be explained in children on the basis of unilateral brain damage. Because bilateral structural and metabolic involvement were not seen in our case, some transient functional disturbances must have occurred before the PET analyses were performed, to elucidate the syndrome. Metabolic deficits in the temporal lobes have been described in Landau-Kleffner syndrome during the active phase of the illness. ${ }^{18}$ It is possible that bilateral epileptic activity, which had already subsided when the patient was admitted, had produced sufficient functional exclusion of the cortical areas in a period critical for language development. ${ }^{11}$ Whereas the prognosis of Landau-Kleffner syndrome is usually poor, the sequellae obtained were in addition slightly exacerbated by the mass effect of the cyst on speech areas, and recovered partly after shunting. Provided this impression is confirmed in further cases, our finding suggests that the PET/FDG method may be a suitable tool for following the neurological evolution of Landau-Kleffner syndrome and for the investigation of functional consequences of arachnoid cysts.

We thank the IBA cyclotron staff, $M$ Cogneau, D Labar, and B Georges for isotope preparation. ADV is senior research assistant and $C M$ is research associate of the Belgian National Fund for Scientific Research. This work was supported by FRSM grants $3 \cdot 4540 \cdot 84$ and $3 \cdot 4560 \cdot 87$

1 Shaw CM, Alvord Jr EC. "Congenital arachnoid" cyst and their differential diagnosis. In: Vinken PJ, Bruin $\mathrm{GW}$, eds. Handbook of clinical neurology Vol 31 Amsterdam: North Holland 1977:75-135.

2 Harsh GR, Edwards MRS, Wilson CB. Intracranial arach noid cysts in children. $\mathcal{F}$ Neurosurg 1986;64:835-42.

3 Oberbauer RW, Haase J, Pucher R. Arachnoid cysts in children: a European co-operative study. Child Nerv Syst 1992;8:281-6.

4 De Volder AG, Francart J, Laterre C, Dooms G, Bol A Michel C, Goffinet AM. Decreased glucose utilization in the striatum and frontal lobe in probable striatonigral degeneration. Ann Neurol 1989;26:239-47.

5 Michel C, Bol A, De Volder AG, Goffinet AM. Online brain attenuation correction in PET: towards a fully automated data handling in a clinical environment. Eur f Nucl Med 1989;15:712-8.

6 Phelps ME, Huang SC, Hoffman EJ, et al. Tomographic measurement of local cerebral glucose metabolic rate in humans with [F18]-2-fluoro-2-deoxy-D-glucose: validation of the method. Ann Neurol 1979;6:371-88.

7 Kretschmann HJ, Weinrich W. Neuroanatomy and cranial computed tomography. New York, NY: Georg Thieme Computed tomogr 1986.

8 De Volder AG, Goffinet AM, Bol A, Michel C, de Barsy $\mathrm{T}$, Laterre C. Brain glucose metabolism in postanoxic syndrome. Arch Neurol 1990;47:197-204.

9 Chugani HT, Phelps ME. Maturational changes in cerebral function in infants determined by [18]FDG positron emission tomography. Science 1986;231:840-3.

10 Camargo EE, Szabo Z, Links JM, Sostre S, Dannals RF Wagner HN. The influence of biological and technica factors on the variability of global and regional brain metabolism of 2-[18F]Fluoro-2-deoxy-D-glucose. Cereb Blood Flow Metab 1992;12:281-9.

11 Aicardi J. Syndrome of acquired aphasia with seizure disorder: epileptic aphasia, Landau-Kleffner syndrome, and verbal auditory agnosia with convulsive disorder. In: verbal auditory agnosia with convulsive disorder. In: Epilepsy in children. International Review of Child

12 Lyon G, Van Coster R. Porencephaly and arachnoid cysts. Curr Ther Neurol Dis 1987;2:77-82.

13 Paetau R, Kajola M, Karhu J, et al. Magnetoencephalographic localization of epileptic cortexImpact on surgical treatment. Ann Neurol 1992;32. 106-9.

14 Lyons MK, Meyer FB. Cerebrospinal fluid physiology and the management of increased intracranial pressure. Mayo Clin Proc 1990;65:684-707.

15 Petersen SE, Fox PT, Posner MI, Mintun M, Raichle ME. Positron emission tomographic studies of the cortical anatomy of single-word processing. Nature 1988;331: 585-9.

16 Wise $R$, Chollet $F$, Hadar U, Friston $K$, Hoffner $E$, Frackowiak R. Distribution of cortical neural networks Frackowiak R. Distribution of cortical neural networks involved in word compre

17 Zatorre RJ, Evans AC, Meyer E, Gjedde A. Lateralization of phonetic and pitch discrimination in speech processing. Science 1992;256:846-9.

18 Maquet $P$, Hirsch E, Dive D, Salmon E, Marescaux C Franck G. Cerebral glucose utilization during sleep in Landau-Kleffner syndrome: a PET study. Epilepsia 1990;31:778-83. 